\title{
Chronic kidney disease and role of palliative care
}

\begin{abstract}
Patients with end-stage kidney disease can have complex comorbidities. Nephrologist chooses dialysis over conservative management. But, thinking about quality of life for a patient, collaboration of palliative care with nephrology is the need of hour. Palliative care can provide support with symptom management, advance care planning. Optimal care may be provided to the patients if palliative care is integrated with nephrology. Change in provision of services, simultaneously balancing the need for dialysis and palliative care needs to be taken into account.
\end{abstract}

Keywords: chronic kidney disease, palliative care, pain in CKD

\author{
Volume 2 Issue 6 - 2018
}

\author{
Shalini Saini,' Dhawal Arora ${ }^{2}$ \\ 'Department of Anaesthesia and Pain management, Himalayan \\ Institute of Medical Sciences, India \\ ${ }^{2}$ Department of Medicine, Himalayan Institute of Medical \\ Sciences, India
}

Correspondence: Shalini Saini, Assistant Professor, Department of Anaesthesia and Pain management, Himalayan Institute of Medical Sciences, India, Email drshafinisaini28@gmail.com

Received: August 16, 2017| Published: November 30, 2018

\section{Introduction}

The population of chronic kidney disease $(\mathrm{CKD})$ patients is ever increasing across the globe. Worldwide, over 1.4 million people receive renal replacement therapy ${ }^{1}$ and the incidence is growing annually by approximately $8 \% .{ }^{2}$ The approximate prevalence of CKD in India is 800 per million population (pmp), and the incidence of end-stage renal disease (ESRD) in India is $150-200 \mathrm{pmp}^{3}{ }^{3}$ These patients have a shortened life expectancy and a high burden of symptoms. They may be benefitted from early palliative care interventions. Palliative care help in relieving suffering and also, provide best possible measures to improve quality of life for both patient as well as their families irrespective of the stage of disease, in unison with their values and preferences.

\section{Why the need of palliative care?}

Skills of palliative care should be incorporated into the present medical system to treat CKD and ESRD patients. The principal reasons are as follows: firstly, life expectancy of these patients is significantly shortened. Just above half of dialysis patients (52\%) are still alive 3 years after the start of RRT. ${ }^{4}$ Secondly, patients with CKD and ESRD suffer a spectrum of symptoms such as pain, fatigue, itching, and difficulty with sleep which need to be taken care. Thirdly, financial burden of dialysis is huge for the patient, family as well as the government. In the UK, there were 54,824 adult patients receiving renal replacement therapy in $2013 .{ }^{5}$ The mean annual cost of dialysis per patient is estimated at $£ 27000 .{ }^{5}$ Provision of treatment for ESRD is predicted to consume approximately $2 \%$ of the annual National Health Service budget ${ }^{6}$ influenced by disproportionate numbers of older, frailer, dependent patients.

In consideration of the high symptom burden and the low survival rate for dialysis patients, the American Society of Nephrology (ASN) and the Renal Physicians Association (RPA) have recommended that dialysis

facilities incorporate palliative care into their treatment of patients. ${ }^{7,8}$ Nephrologists have been encouraged to obtain education and skills in palliative care, and dialysis facilities have been urged to developed protocols, policies, and programs to ensure that palliative care is provided to their patients. ${ }^{8}$

\section{Symptom assessment}

Identification and management of symptoms in renal patients is very crucial. However, evidence shows that symptoms in renal disease patients are not assessed properly and often go unrecognised.

Tools such as the Modified Edmonton Symptom Assessment System $^{9-11}$ (m-ESAS v. 2) and Palliative Care Outcome ScaleRenal $^{12,13}$ (POS-renal) are appropriate for routine clinical screening for pain in renal programs and help redirect care to a more patient centered model.

\section{Symptom management}

\section{Pain in CKD}

It is well documented in the literature that severe pain is prevalent amongst CKD patients: various publications highlight CKD patients' experience with pain. Most of these data come from prevalent hemodialysis patients (with 36 studies examining over 5200 patients) and show that over $58 \%$ of CKD patients experience pain and $49 \%$ of patients rate their pain as moderate or severe. ${ }^{14}$ The sources of pain were musculoskeletal (62\%) followed by other organ systems including gastrointestinal $(13 \%)$, genitourinary $(10 \%)$, haematological/oncological $(10 \%)$, central and peripheral nervous system $(9 \%)$, cardiovascular $(7 \%)$ and others $(10 \%) .{ }^{15}$ WHO ladder can be used most of the time to manage pain symptoms taking in consideration about the renal function. ${ }^{16}$

Step 1: Paracetamol is safe drug which can be used in renal failure.

NSAIDs should be avoided as far as possible because they will further impair renal function.

Step 2: Weak opiods such as Tramadol may be used but the dose should be reduced or the dosing interval should be increased, in addition to monitoring for any adverse effects. Other opiods: codeine, dihydrocodeine and their derivatives should be avoided with the risk of accumulation of the metabolites.

Step 3: Strong opiods include Fentanyl which has no active metabolites and only $10 \%$ of the unchanged drug is excreted by the kidneys. There is a possibility of drug accumulation but cautious titration and careful monitoring may prevent toxicity. Morphine 
is metabolised in the liver to many active metabolites including morphine-3-glucoronide and morphine-6 glucoronide. These metabolites are potent and can cause significant respiratory depression and drowsiness. Both the unchanged drug and the metabolites are excreted by the kidneys and are found to accumulate in renal failure, leading to significant toxicity. These drugs should be avoided in patients with CKD Stage 4 and $5(\mathrm{eGFR}<30 \mathrm{ml} / \mathrm{min})$. Oxycodone is another strong opiod which is metabolised in the liver to active metabolites, noroxycodone and oxymorphone. Both oxycodone and its metabolites are cleared by the kidneys, thus accumulation can occur. If required, the short-acting form should be used at a low dose with an increased dosing interval.

\section{Management of nausea and vomiting}

Evaluating the likely cause of nausea and vomiting is very important as different anti-emetics work on different receptors. Uraemia may be responsible for accompanied persistent nausea which is best managed by drugs which act at the chemoreceptor trigger zone such as Haloperidol which is the drug of choice for uraemia induced nausea. However, the dose should be reduced due to risk of accumulation and increased cerebral sensitivity. Domperidone/ metoclopramide are preferred if delayed gastric emptying is suspected which is commonly seen in diabetic or uraemic neuropathy. Metoclopramide can accumulate in CKD patients with an increased risk of extrapyramidal reactions, therefore dose reduction is required. If nausea and vomiting becomes

refractory, Levomepromazine can be used which is a broad spectrum anti-emetic acting at many receptors.

\section{Management of Uraemia-induced Pruritus}

Pruritus can be triggered due to various factors including uraemiarelated abnormalities (calcium, phosphorus and parathyroid hormone metabolism), accumulation of uraemic toxins, systemic inflammation, cutaneous xerosis, the opioid system and serotonergic system. Management modalities include dialysis, correction of calcium, phosphorus, Gabapentin, phototherapy. However, there is limited evidence with these options.

\section{Advance care planning}

Advance care planning provides direction to healthcare professionals when a person is not in a position to either make and/ or communicate their own healthcare choices. Advance care planning allows for a more patient centred approach rather than the focus being primarily on disease, for instance, centred around dialysis decisions. Advance care planning has been recommended as a central tenet of CKD, ESRD, and cancer patient care. ${ }^{17}$ The American Society of Nephrology and Renal Physicians Association have recommended that advance care planning for CKD and ESRD patients including a patient-specific estimate of prognosis and shared decision-making occur prior to the initiation of dialysis. ${ }^{8,18}$ Nephrologists are responsible for advance care planning, although aspects of it can be delegated to other nephrology personnel. ${ }^{17}$ Advance care planning is important for kidney cancer patients because it can ensure that patients' wishes for end-of-life care are respected, that unwanted interventions are avoided, and that patients and their families are satisfied with the care provided. ${ }^{17}$

\section{Conclusion}

Increasing number of $\mathrm{CKD}$ patients is gaining attention of leading nephrologist worldwide to incorporate palliative care in the management of these patients to reduce burden on the families, economy. Clinicians need extensive and specialised expertise in pain symptom management and skills in communication to meet the needs of this population. The ideal approach calls for collaboration between the renal healthcare team and palliative care consultants. ${ }^{19}$ Discussion with the patient well in time, with family members and care givers would allow planning for the last days of their lives which could allow a dignified death.

\section{Acknowledgments}

None.

\section{Conflicts of interest}

The authors declare there is no conflicts of interest.

\section{References}

1. Moeller S, Gioberge S, Brown G. ESRD patients in 2001: global overview of patients, treatment modalities and development trends. $\mathrm{Ne}$ phrol Dial Transplant. 2002;17(12):2071-2076.

2. Schieppati A, Remuzzi G. Chronic renal disease as a public health problem: epidemiology, social, and economic implications. Kidney Int Suppl. 2005;98:7-10.

3. Aggarwal SK, Srivastava RK. Chronic kidney disease in India: challenges and solutions. Nephron Clin Pract. 2009;111(3):c197-c203.

4. United States Renal Data System. 2013 USRDS Annual Data Report: Atlas of Chronic Kidney Disease and End-Stage Renal Disease in the United States, Bethesda, MD, National Institutes of Health, National Institutes of Diabetes and Digestive and Kidney Diseases, 2013.

5. Shaw C, Pitcher D, Pruthi R, et al. UK Renal Registry $16^{\text {th }}$ Annual Report: Chapter 2 UK RRT Prevalence in 2012: National and Centre-Specific Analyses. Nephron Clin Pract. 2013;125(1-4):29-53.

6. Kerr M, Bray B, Medcalf J, et al. Estimating the financial cost of chronic kidney disease to the NHS in England. Nephrol Dial Transplant. 2012;27 Suppl 3:iii73-80.

7. Galla JH. Clinical practice guideline on shared decision-making in the appropriate initiation of and withdrawal from dialysis. The Renal Physicians Association and the American Society of Nephrology. J Am Soc Nephrol. 2000;11(7):1340-1342.

8. Renal Physicians Association. Shared Decision-Making in the Appropriate Initiation of and Withdrawal from Dialysis. 2nd ed. Rockville: Renal Physicians Association; 2010.

9. Davison SN, Jhangri GS, Johnson JA. Cross-sectional validity of a modified Edmonton symptom assessment system in dialysis patients: a simple assessment of symptom burden. Kidney Int. 2006;69(9):16211625 .

10. Davison SN, Jhangri GS, Johnson JA. Longitudinal validation of a modified Edmonton symptom assessment system (ESAS) in haemodialysis patients. Nephrol Dial Transplant. 2006;21(11):3189-3195.

11. Walke LM, Byers AL, McCorkle R, et al. Symptom assessment in community-dwelling older adults with advanced chronic disease. J Pain Symptom Manage. 2006;31(1):31-37. 
12. Murphy EL, Murtagh FE, Carey I, et al. Understanding symptoms in patients with advanced chronic kidney disease managed without dialysis: use of a short patient-completed assessment tool. Nephron Clin Pract. 2009;111(1):c74-c80.

13. Hearn J, Higginson IJ. Development and validation of a core outcome measure for palliative care: the palliative care outcome scale. Palliative Care Core Audit Project Advisory Group. Qual Health Care.1999;8(4):219-227.

14. Davison SN. Pain, Analgesics, and Safety in Patients with CKD. Clin J Am Soc Nephrol. 2015;10(3):350-352.

15. Dewar K, Hashmi S, Pham PT, et al. Chronic kidney disease and pain J Am Soc Nephrol. 2006.
16. Douglas CA. Palliative care for patients with advanced chronic kidney disease. J R Coll Physicians Edinb. 2014;44(3):224-231.

17. Holley JL, Davison SN. Advance care planning for patients with advanced CKD: A need to move forward. Clin J Am Soc Nephrol. 2015;10(3):344-346.

18. Williams AW, Dwyer AC, Eddy AA, et al. Critical and honest conversations: The evidence behind the "Choosing Wisely" campaign recommendations by the American Society of Nephrology. Clin J Am Soc Nephrol. 2012;7(10):1664-1672.

19. Kafkia T, Chamney M, Drinkwater A, et al. Pain in chronic kidney disease: prevalence, cause and management. $J$ Ren Care. 2011;37(2):114-122. 